\title{
Fracture Toughness of Vapor Grown Carbon Nanofiber-Reinforced Polyethylene Composites
}

\author{
A. R. Adhikari, ${ }^{1}$ E. Partida, ${ }^{1}$ T. W. Petty, ${ }^{1}$ R. Jones, ${ }^{1}$ K. Lozano, ${ }^{1}$ and C. Guerrero ${ }^{2}$ \\ ${ }^{1}$ Department of Mechanical Engineering, University of Texas-Pan American, Edinburg, TX 78539, USA \\ ${ }^{2}$ Facultad de Ingeniería Mecánica y Eléctrica, Universidad Autónoma de Nuevo León, San Nicolás de los Garza, 66451, \\ Nuevo León, CP, Mexico
}

Correspondence should be addressed to K. Lozano, lozanok@utpa.edu

Received 2 November 2008; Accepted 22 June 2009

Recommended by Alan K. T. Lau

The impact fracture behavior of a vapor grown carbon nanofiber (VGCNF) reinforced high-density polyethylene (PE) composite was evaluated. The samples consisting of pure PE and composites with $10 \mathrm{wt} \%$ and $20 \mathrm{wt} \%$ of VGCNFs were prepared by a combination of hot-pressing and extrusion methods. Extrusion was used to produce samples with substantially different shear histories. The fracture behavior of these samples was analyzed using the essential work of fracture (EWF) approach. The results showed an increase of $292 \%$ in the essential work of fracture for the loading of $10 \mathrm{wt} \%$. Further increasing fiber loading to $20 \mathrm{wt} \%$ caused the essential work of fracture to increase only $193 \%$ with respect to the unmodified material. Evaluation of the fracture surface morphology indicated that the fibril frequency and microvoid size within the various fiber loadings depended strongly on processing conditions.

Copyright (c) 2009 A. R. Adhikari et al. This is an open access article distributed under the Creative Commons Attribution License, which permits unrestricted use, distribution, and reproduction in any medium, provided the original work is properly cited.

\section{Introduction}

Polyethylene is characterized by a great capacity to absorb energy despite its low modulus of elasticity [1]. Because of its high toughness it offers promise as a matrix for highly damage tolerant composites. However development of adequate adhesion between $\mathrm{PE}$ and high performance reinforcements has been a challenge. Nanofibers show great promise for modification of existing materials due to the combination of their small size and surface compatibility. Their high thermal, electrical, and mechanical properties offer the prospect of substantial improvements in polymeric systems. This prospect is further enhanced by the strong natural adhesion nanofibers with many thermoplastic matrices [2-6].

Prior studies have shown that VGCNFs interact strongly with polymeric matrices and enhance several properties. PE/VGCNF composites have been found to produce a simultaneous increase in both storage (elastic) and loss (viscous dissipation) modulus as measured by dynamic mechanical analysis [7]. Tensile tests of these composites show a remarkable increase in elongation to failure with increased shear history and an apparently new mechanism of void stabilization permitting the formation of widespread stable subcritical voids in the deformed polymer [8]. The current work extends the study of these materials to the regime of dynamic impact behavior.

The highly nonlinear nature of the fracture process in $\mathrm{PE}$ requires the use of nonlinear fracture analysis. The most widely used methods are the J-integral [9] and the essential work of fracture (EMF) $[10,11]$. In the recent years, the concept of EWF has been broadly applied to the evaluation of fracture toughness in ductile polymers and their composites due to its greater simplicity when compared to J-integral measurement [12-15]. This theory was initially proposed by Broberg [16] in 1968 and further developed by Mai and others $[11,17]$. The theory poses that the total energy necessary to fracture a cracked material $\left(W_{f}\right)$ contains two components the essential work of fracture $\left(W_{e}\right)$ and nonessential work or plastic work $\left(W_{p}\right)$ (see Figure 1)

$$
W_{f}=W_{e}+W_{p} .
$$

$W_{e}$ is the essential work required to rupture in its inner fracture process zone. For a given material thickness $(t), W_{e}$ 


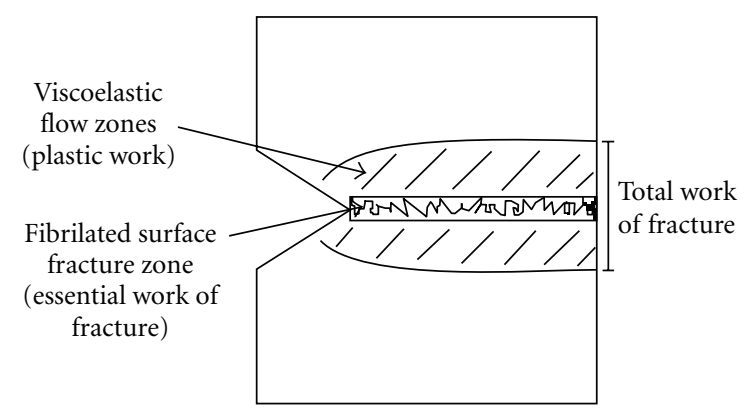

FIGURE 1: Schematic diagram of flow zones during fracture.

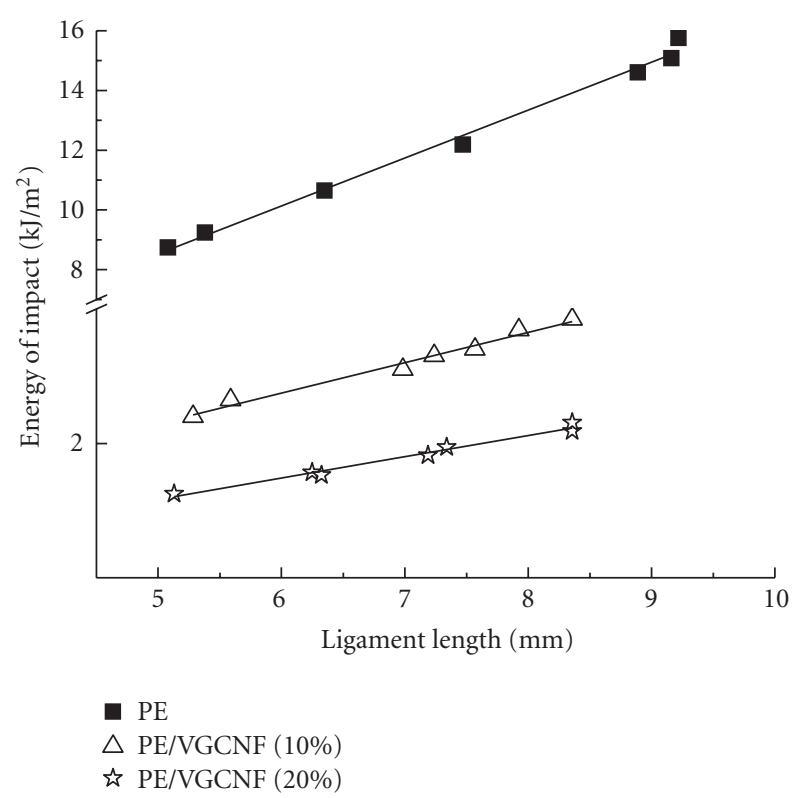

FIgURE 2: A representative plot of energy of impact $\left(w_{f}\right)$ versus ligament length $(\ell)$.

is proportional to the ligament length $(\ell) . W_{p}$ is the energy consumed by mechanisms of deformation in the outer plastic zone and is a volume energy proportional to $\ell^{2}$.

The expression in (1) can be expanded to

$$
W_{f}=w_{e} \ell t+\beta w_{p} \ell^{2} t
$$

In terms of specific values, total specific work of fracture, $w_{f}$ is given by

$$
w_{f}=\left(\frac{W_{f}}{\ell t}\right)=w_{e}+\beta w_{p} \ell
$$

where $w_{e}$ and $w_{p}$ are the essential specific work of fracture and the specific nonessential work (or specific plastic work), respectively. The term $\beta$ is a form factor for the plastic zone. Equation (3) provides the $w_{e}$ and $w_{p}$ from the intercept and the slope of corresponding linear regression curve of the plot of $w_{f}$ as a function of $\ell$. A representative plot of $w_{f}$ as a function of $\ell$ is shown in Figure 2.
In this study, measurements of energy to fracture under impact using the method of essential work of fracture were made. Fracture surface morphology was also evaluated to determine changes in the fracture mechanism caused by nanofibers reinforcement.

\section{Experimental}

2.1. Materials. The systems evaluated were based on highdensity polyethylene (Marflex PE CL-L-R-240370) provided by Chevron-Philips Chemical Co. and vapor grown carbon nanofibers (Pyrograf III) (VGCNFs) provided by Applied Sciences. The fibers were purified before use according to procedures developed and described elsewhere [18]. Purification of the fibers was done with a process of refluxing nanofibers in dichloromethane followed by rinsing with deionized water. The purpose of purification is to remove amorphous carbon and untangle nested fiber bundles. It also serves to lightly functionalize the surface of the fibers, making them more compatible with some polymer matrices though this may not be critical to performance in PE.

2.2. Processing. After purification, the fibers were introduced into the PE matrix using a Haake Polylab 600 mixer which subjects the composite to high shear stresses. Mixing was done at a nominal temperature of $190^{\circ} \mathrm{C}$ for a total of 16 minutes at varied mixing speeds. A 2-minute mix of pure $\mathrm{PE}$ at $90 \mathrm{rpm}$ was followed by fiber addition, 11 minutes at $30 \mathrm{rpm}$, and 3 minutes at $60 \mathrm{rpm}$. The length of each processing step was determined by the time necessary to produce a constant shearing torque measured at the mix head. The resulting material was hot pressed (Carver Hot-Press model 3912) and again extruded using a Haake Rheomixer 600 with an extrusion screw speed of $40 \mathrm{rpm}$ and a die temperature of $190^{\circ} \mathrm{C}$.

After extrusion, the film was stretched by a Haake Tape Postex 600 to create a tape. To introduce varying shear stress histories generated by the extensional flow, drawing was done at 10 and $20 \mathrm{rpm}$. The resulting tape was pelletized once more and then molded to the final specimen size and thickness in a hydraulic heated press (PHI model 100-1a). The preparation combinations are summarized in Table 1. Rectangular $63.5 \mathrm{~mm} \times 12.7 \mathrm{~mm} \times 3.2 \mathrm{~mm}$ bars, with a singleedge-notched 3-point bending configuration, were used for impact testing.

2.3. Characterizations. Tests were done at a temperature of $22^{\circ} \mathrm{C}$ in the Dynatup 830I drop weight system with a span length of $50 \mathrm{~mm}$ and an impact velocity of $2.5 \mathrm{~m} / \mathrm{s}$. Eight specimens were prepared and tested for each treatment combination. The exact length of the ligament was measured by optical microscopy on an Olympus T4560 imaging analyzer. The specimen was made with a saw $1 \mathrm{~mm}$ gap and the tip of crack with a fresh razor blade. It was not necessary to immerse in liquid nitrogen because this sample presented a brittle fracture. The fracture morphology was studied using Scanning electron microscopy (SEM). 
TABle 1: Process flow used for neat PE and PE/VGCNF composites preparation, MP samples were mixed and pressed; MPEP 10 RMP samples were mixed, pressed, extruded at $10 \mathrm{rpm}$ and pressed again; MPEP 20 RPM samples were mixed pressed extruded at $20 \mathrm{rpm}$ and pressed again.

\begin{tabular}{|c|c|c|c|c|c|}
\hline \multirow{3}{*}{ Sample } & \multirow{3}{*}{ Mixed } & \multirow{3}{*}{ Hot pressed } & \multicolumn{2}{|c|}{ Process type } & \multirow{3}{*}{ Mold pressed } \\
\hline & & & \multicolumn{2}{|c|}{ Extruded velocity of elongation (rpm) } & \\
\hline & & & 10 & 20 & \\
\hline \multicolumn{6}{|l|}{ Pure PE } \\
\hline MP & $\times$ & $\times$ & - & - & $\times$ \\
\hline MPEP 10 RPM & $\times$ & $\times$ & $\times$ & - & $\times$ \\
\hline MPEP 20 RPM & $\times$ & $\times$ & - & $\times$ & $\times$ \\
\hline \multicolumn{6}{|c|}{ PE/VGCNF (10\% wt) } \\
\hline MP & $\times$ & $\times$ & - & - & $\times$ \\
\hline MPEP 10 RPM & $\times$ & $\times$ & $\times$ & - & $\times$ \\
\hline MPEP 20 RPM & $\times$ & $\times$ & - & $\times$ & $\times$ \\
\hline \multicolumn{6}{|c|}{ PE/VGCNF (20\% wt) } \\
\hline MP & $\times$ & $\times$ & - & - & $\times$ \\
\hline MPEP 10 RPM & $\times$ & $\times$ & $\times$ & - & $\times$ \\
\hline MPEP 20 RPM & $\times$ & $\times$ & - & $\times$ & $\times$ \\
\hline
\end{tabular}

\section{Results and Discussion}

3.1. Fracture Analysis. Impact results of PE and its composites were compared using single-edge notched tension specimen. A representative plot of total energy of fracture versus ligament length is shown in Figure 2. It clearly shows the effect of increased flow stress with nanofiber addition. The higher flow stress results in increased constraint in the ligament and a reduction in gross viscoplastic flow in the ligament. The reduced gross plasticity reduces the total energy of fracture relative to the unreinforced material. Table 2 summarizes the values of $w_{e}, w_{p}$ and total energy. $w_{e}$ values for all samples are plotted in Figure 3. The unmodified PE shows an increase in $w_{e}$ (local fracture energy) but an overall reduction in fracture energy. The fiber modified systems show a clear increase in $w_{e}$ with increasing shear history while total fracture energy falls relative to the unmodified system. In other words, increased processing improves the local material toughness in the process zone while fiber addition reduces the overall toughness by constraining gross plasticity in the specimen.

The increase in toughness is higher for the $10 \mathrm{wt} \%$ PE/VGCNF composite than for the $20 \mathrm{wt} \%$ fiber system which could indicate a countervailing effect of fiber loading. Essential work of fracture in the fracture zone corresponds to the energy required to debond PE and VGCNF, and to deform the polymer matrix [19]. Therefore, the likely mechanism for the improvement in toughness is improvement in fiber/polymer adhesion and better dispersion of the fibers. These improvements result in greater void growth through stable fibril formation (see morphology section). At the same time, the plastic work, $w_{p}$, generally falls, suggesting greater localization of the fracture process and reduction of gross plasticity. The smaller increasein toughness observed in the

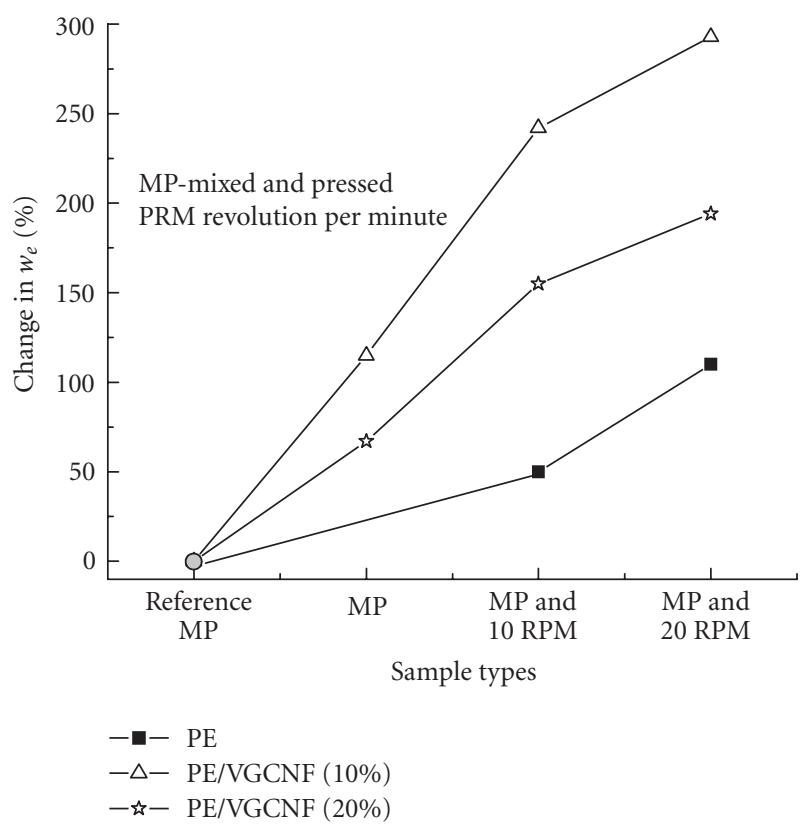

FIgURE 3: Comparison of $\%$ change of $w_{e}$ with process parameters.

higher fiber loaded system indicates that the toughening phenomenon is primarily matrix driven and is not due directly to fiber breakage or other fiber driven energy consuming process. Eventually the higher loading of fibers $(20 \mathrm{wt} \%)$ results in a reduction in the work of fracture through restriction of ductile matrix deformation (caused by constraint as well as a reduction in the volume of polymer available). This leads to a diminution in the specific plastic work of the material. This is similar to the behavior seen in traditional short-glass fiber reinforced polymers [20, 21]. 

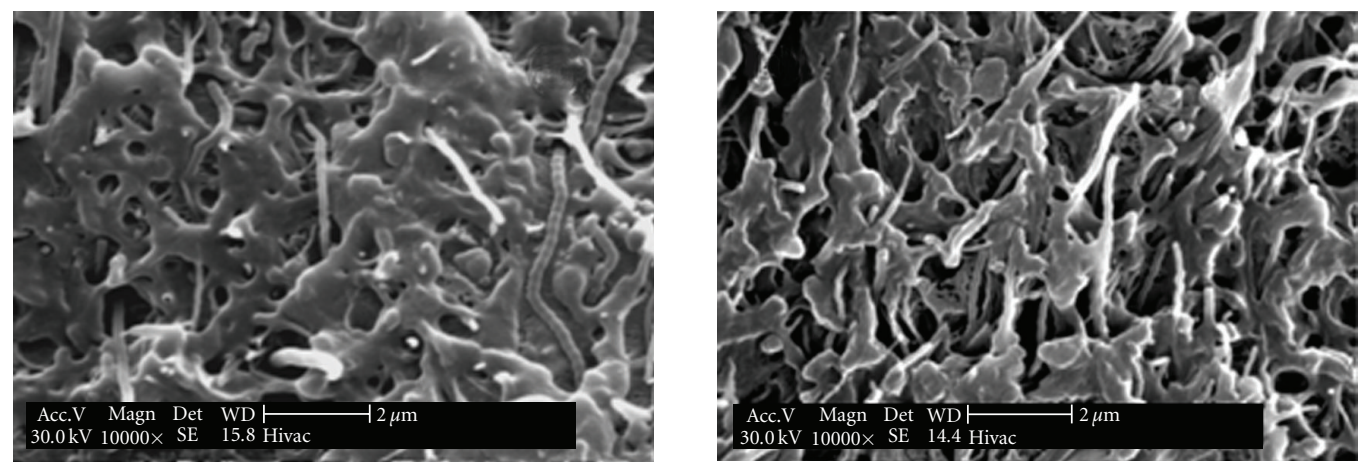

(a)
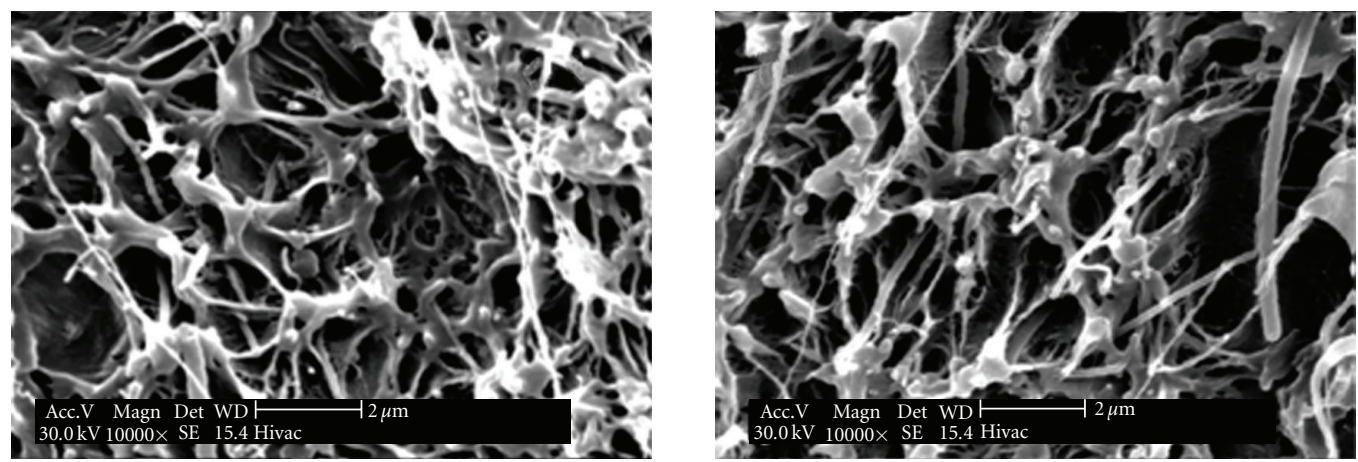

(b)
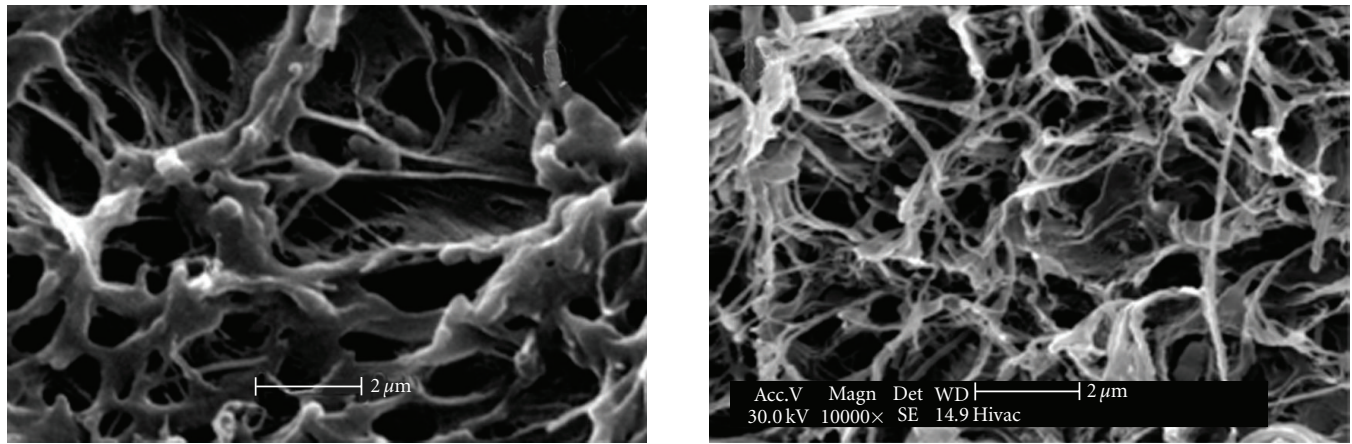

(c)

FIGURE 4: Fracture surface SEM micrograph of 10\% (left) and 20\% (right) PE/VGCNF Composite: (a) undrawn, (b) $10 \mathrm{rpm}$ drawn, and (c) 20 rpm drawn.

The substantial improvement seen in process zone energy dissipation with the addition of nanofibers in an impact environment suggests that these materials should show substantial improvement in resistance to slow stable crack growth or stress corrosion cracking which are quasistatic fracture processes which do not involve significant gross plasticity. That will be the subject of future research.

3.2. Morphology. Changes in the fracture process are usually reflected in the morphology of the fracture surface; therefore, specimens were evaluated using the scanning electron micro- scope. It should be noted that the high level of fibrillation seen in these impact test specimens, especially the levels seen in the drawn materials, are more consistent with quasistatic fracture in neat polyethylene systems than with impact. Nanofiber loading makes possible energy dissipating fracture processes normally prevented by high crack velocities.

Representative micrographs are shown in Figure 4 for PE/VGCNF composites with fiber contents of 10 and $20 \mathrm{wt} \%$ and three processing levels. The fibers were clearly well dispersed in both systems. The number and length of fibrils, along with voids developed within the fracture process zone, increase dramatically after the shearing process $(10 \mathrm{rpm}$ and 
TABLE 2: EWF parameters for neat PE and PE/VGCNF composites.

\begin{tabular}{|c|c|c|c|c|c|}
\hline Samples & $\begin{array}{c}w_{e} \\
\left(\mathrm{~kJ} / \mathrm{m}^{2}\right)\end{array}$ & $\begin{array}{c}\beta w_{p} \\
\left(\mathrm{~kJ} / \mathrm{m}^{2}\right)\end{array}$ & $\begin{array}{c}\text { Ligament } \\
(\mathrm{mm})\end{array}$ & $r^{2}$ & $\begin{array}{c}\text { Total energy } \\
\left(\mathrm{kJ} / \mathrm{m}^{2}\right)\end{array}$ \\
\hline \multicolumn{6}{|l|}{ PE } \\
\hline MP & 0.4978 & 1.606 & 8.890 & 0.993 & 2.0799 \\
\hline MPEP at $10 \mathrm{RPM}$ & 0.7058 & 1.2122 & 9.017 & 0.995 & 1.918 \\
\hline MPEP at 20 RPM & 0.9914 & 1.1704 & 8.128 & 0.991 & 1.8828 \\
\hline \multicolumn{6}{|c|}{ PE/VGCNFs (10\% wt.) } \\
\hline $\mathrm{MP}$ & 1.0156 & 0.2262 & 7.925 & 0.984 & 1.2418 \\
\hline MPEP at $10 \mathrm{RPM}$ & 1.6165 & 0.1216 & 8.255 & 0.980 & 1.7381 \\
\hline MPEP at $20 \mathrm{RPM}$ & 1.8531 & 0.1471 & 8.001 & 0.992 & 2.0002 \\
\hline \multicolumn{6}{|c|}{ PE/VGCNFs (20\% wt.) } \\
\hline $\mathrm{MP}$ & 0.7891 & 0.1588 & 8.357 & 0.980 & 0.9479 \\
\hline MPEP at $10 \mathrm{RPM}$ & 1.2015 & 0.0446 & 8.966 & 0.915 & 1.2461 \\
\hline MPEP at 20 RPM & 1.3861 & 0.1012 & 8.636 & 0.977 & 1.4873 \\
\hline
\end{tabular}

$20 \mathrm{rpm}$ ) for $10 \mathrm{wt} \%$ fibers loading. However, the development of fibrils in $20 \mathrm{wt} \%$ composite at higher shearing $(20 \mathrm{rpm})$ is not similar to that of $10 \mathrm{wt} \%$ composites. This can be attributed to the interaction between the nanofibers at higher loading. The observed fracture surface morphology indicates that the higher values of local fracture energy, $w_{e}$, of composites is a result of enhancement in fibrillation and the formation of large stable voids resulting from coalescence of stable voids. The fibers act to stabilize and increase fibrillation thus enhancing the toughness of the matrix in the local process zone.

\section{Conclusion}

The addition of carbon nanofibers to polyethylene improves the ability of the polymer to form large fibril/void structures even under conditions of process zone constraint due to impact loading. This is reflected in an increase in local fracture toughness measured by the essential work of fracture. Further, this local toughness increases with increasing shear history during processing. The strength of this interaction may arise from one or both of two sources. The extended shear and thermal history may cause molecular scission as evidenced by the reduced total toughness of the unmodified system. The resulting free radicals then may bond to the nanofibers, resulting in an extremely strong matrix/fiber interaction. It is also likely that because of their similar structures, polyethylene and VGCNFs will form strong bonds when polymer chains are stretched out along the fiber surfaces. Either mechanism results in a level of interaction which produces properties and fracture processes not heretofore observed in polymer composites.

\section{Acknowledgment}

The authors would like to acknowledge Jiang Zhu at Rice University for SEM pictures.

\section{References}

[1] C. A. Harper and E. M. Petrie, Eds., Plastics Materials and Processes: A Concise Encyclopedia, John Wiley \& Sons, New York, NY, USA, 2003.

[2] G. Galgali, C. Ramesh, and A. Lele, "A rheological study on the kinetics of hybrid formation in polypropylene nanocomposites," Macromolecules, vol. 34, no. 4, pp. 852-858, 2001.

[3] F. H. Gojny and K. Schulte, "Functionalisation effect on the thermo-mechanical behaviour of multi-wall carbon nanotube/epoxy-composites," Composites Science and Technology, vol. 64, no. 15, pp. 2303-2308, 2004.

[4] W. E. Gacitua, A. A. Ballerini, and J. Zhang, "Polymer nanocomposites: synthesis and natural fillers a review," Maderas. Ciencia y Tecnología, vol. 7, pp. 159-178, 2005.

[5] L. Bokobza and J.-P. Chauvin, "Reinforcement of natural rubber: use of in situ generated silicas and nanofibres of sepiolite," Polymer, vol. 46, no. 12, pp. 4144-4151, 2005.

[6] B. Lim, C.-J. Kim, B. Kim, et al., "The effects of interfacial bonding on mechanical properties of single-walled carbon nanotube reinforced copper matrix nanocomposites," Nanotechnology, vol. 17, no. 23, pp. 5759-5764, 2006.

[7] S. Yang, J. Taha-Tijerina, V. Serrato-Diaz, K. Hernandez, and K. Lozano, "Dynamic mechanical and thermal analysis of aligned vapor grown carbon nanofiber reinforced polyethylene," Composites Part B, vol. 38, no. 2, pp. 228-235, 2007.

[8] K. Lozano, S. Yang, and R. E. Jones, "Nanofiber toughened polyethylene composites," Carbon, vol. 42, no. 11, pp. 23292331, 2004.

[9] J. G. Williams, Fracture Mechanics of Polymers, Ellis Horwood, Chichester, UK, 1987.

[10] K. B. Broberg, "Crack-growth criteria and non-linear fracture mechanics," Journal of the Mechanics and Physics of Solids, vol. 19, no. 6, pp. 407-418, 1971.

[11] Y.-W. Mai and B. Cotterell, "On the essential work of ductile fracture in polymers," International Journal of Fracture, vol. 32, no. 2, pp. 105-125, 1986.

[12] R. Lach, K. Schneider, R. Weidisch, A. Janke, and K. Knoll, "Application of the essential work of fracture concept to nanostructured polymer materials," European Polymer Journal, vol. 41, no. 2, pp. 383-392, 2005. 
[13] D. Arencón, J. I. Velasco, V. Realinho, M. Antunes, and M. L. 1. Maspoch, "Essential work of fracture analysis of glass microsphere-filled polypropylene and polypropylene/poly (ethylene terephthalate-co-isophthalate) blend-matrix composites," Polymer Testing, vol. 26, no. 6, pp. 761-769, 2007.

[14] X. L. Wang, R. K. Y. Li, Y. X. Cao, and Y. Z. Meng, "Essential work of fracture analysis for starch filled poly(propylene carbonate) composites," Materials and Design, vol. 28, no. 6, pp. 1934-1939, 2007.

[15] R. E. Jones and W. L. Bradley, "Fracture toughness testing of Polyethylene pipe materials," in ASTM STP 995, vol. 1, pp. 447-456, 1989.

[16] K. B. Broberg, "On stable crack growth," Journal of the Mechanics and Physics of Solids, vol. 23, no. 3, pp. 215-237, 1975.

[17] Y. W. Mai and K. M. Pilko, "The essential work of plane stress ductile fracture of a strain-aged steel," Journal of Materials Science, vol. 14, no. 2, pp. 386-394, 1979.

[18] K. Lozano, B. Files, F. Rodrigues-Macias, and E. V. Barrera, "Purification and functionalization of vapor grown carbon fibers and single wall nanotubes," in Proceedings of the TMS Fall Meeting Symposium Powder Materials: Current Research and Industrial Practices, pp. 333-340, Cincinnati, Ohio, USA, 1999.

[19] J. Karger-Kocsis, Polypropylene: Structure, Blends and Composites, Vol. 3, Chapman \& Hall, London, UK, 1995.

[20] E. C. Y. Ching, R. K. Y. Li, S. C. Tjong, and Y.-W. Mai, "Essential work of fracture (EWF) analysis for short glass fiber reinforced and rubber toughened nylon-6," Polymer Engineering and Science, vol. 43, no. 3, pp. 558-569, 2003.

[21] S. C. Tjong, S. A. Xu, and Y. W. Mai, "Impact fracture toughness of short glass fiber-reinforced polyamide 6,6 hybrid composites containing elastomer particles using essential work of fracture concept," Materials Science and Engineering A, vol. 347, no. 1-2, pp. 338-345, 2003. 

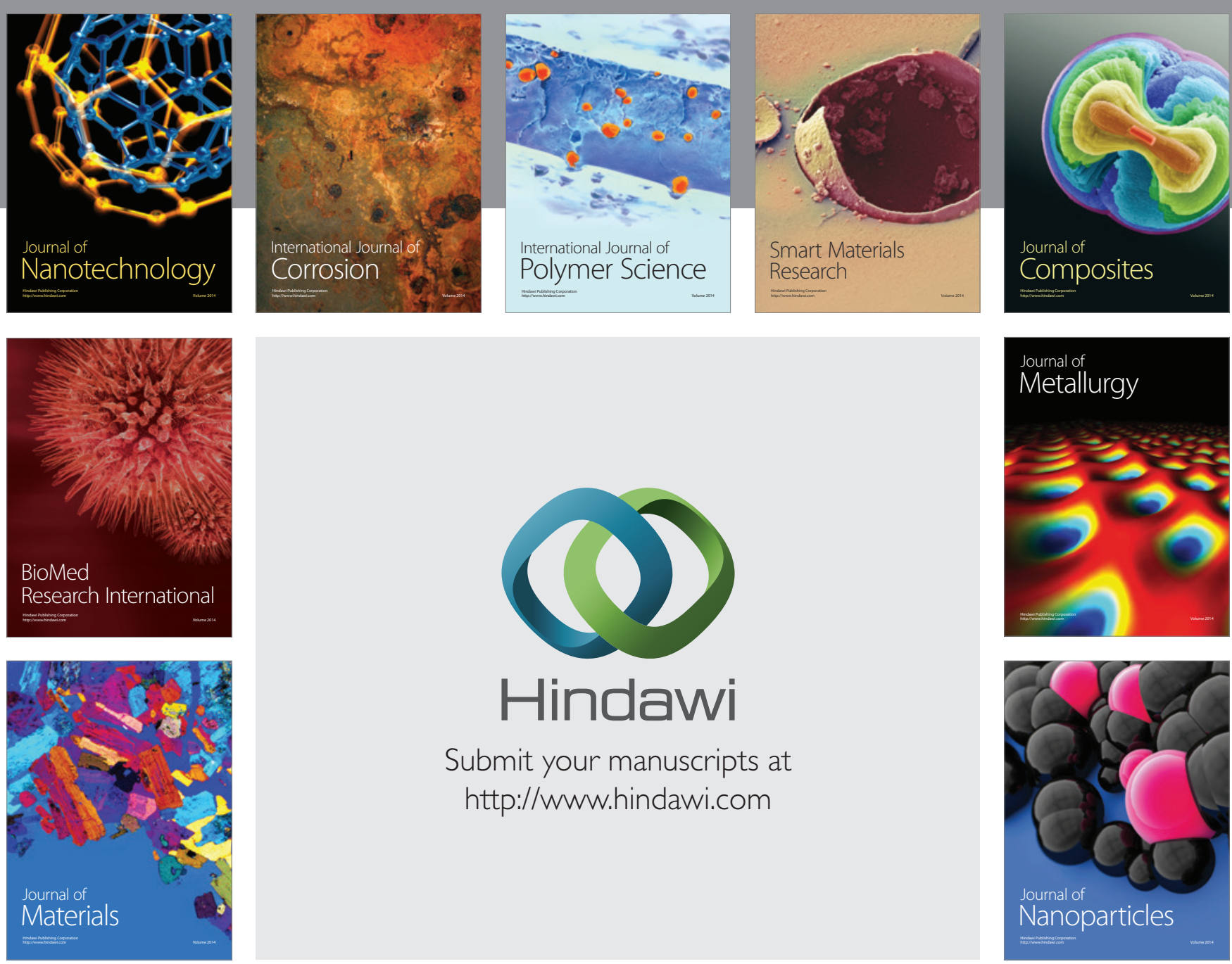

Submit your manuscripts at http://www.hindawi.com
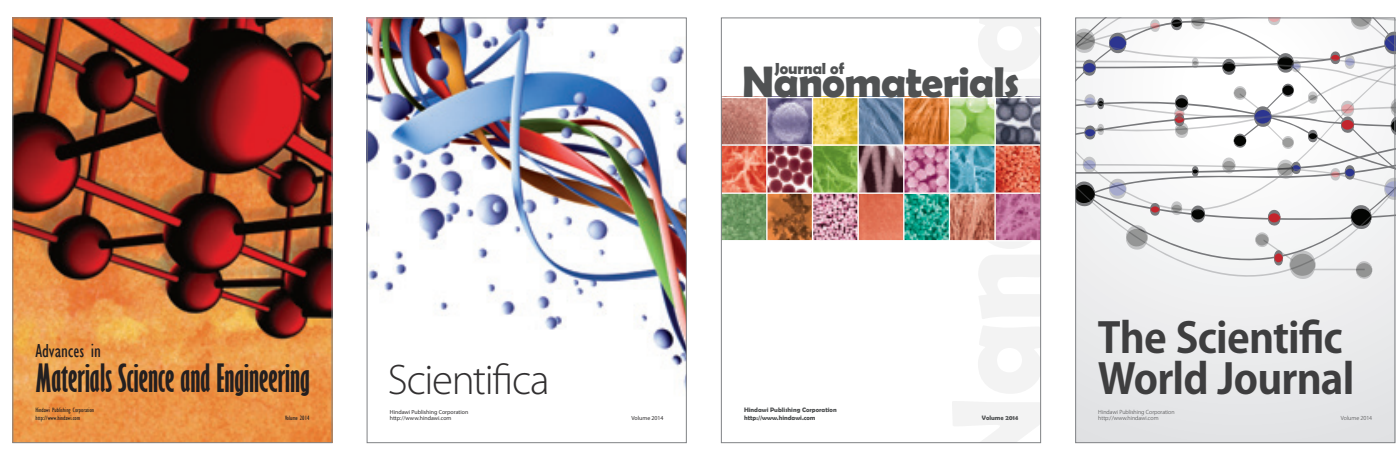

\section{The Scientific World Journal}
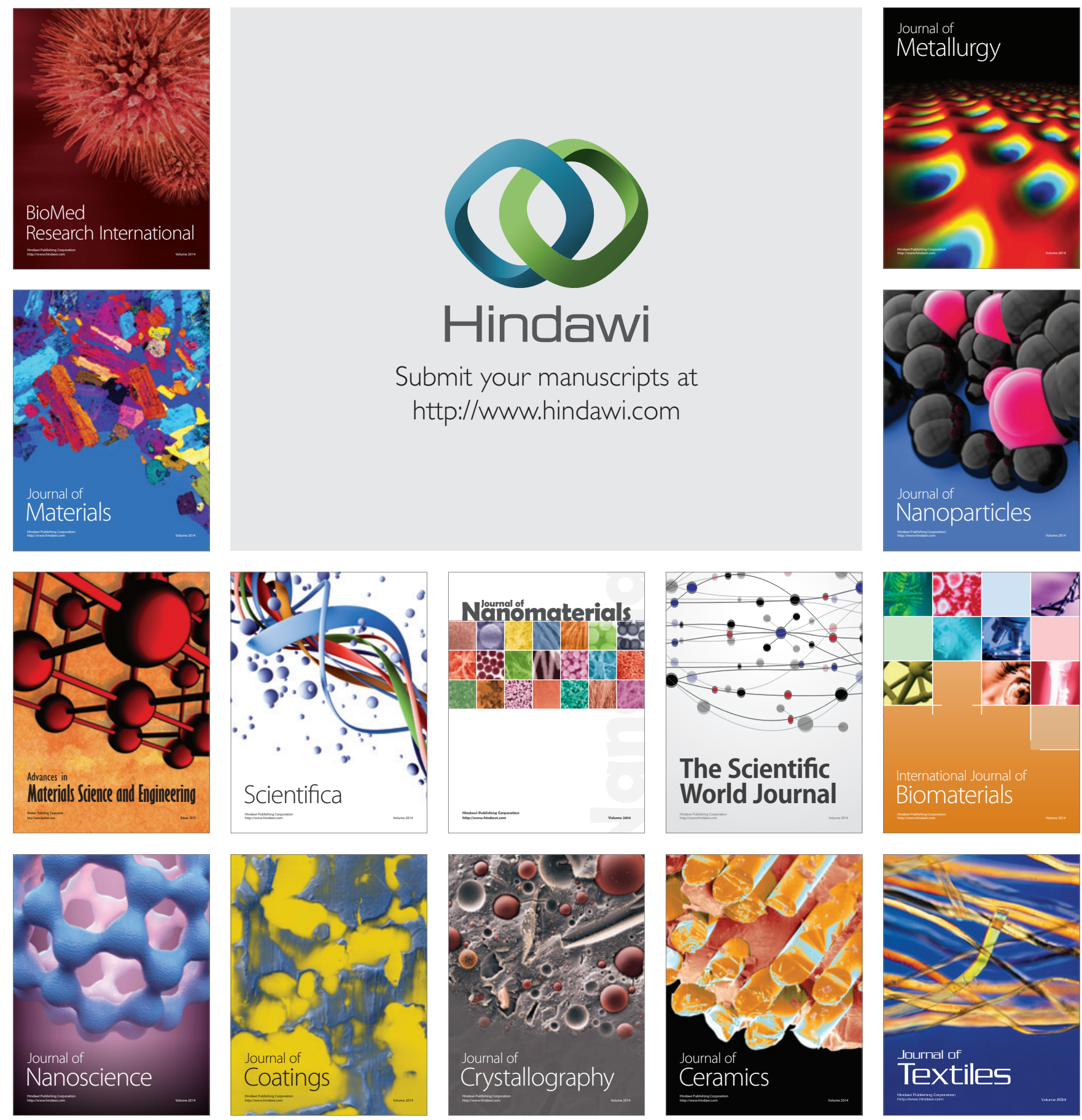